\title{
Antifungal and Photocatalytic Activity of Smart Paint Containing Porous Microspheres of TiO,
}

\author{
Suélen Maria de Amorim ${ }^{a}{ }^{\circledR}$, Joice Cristine Sapatieri ${ }^{a}$, Denise Esteves Moritz ${ }^{a}$, Michele Di Domenico ${ }^{b}$, \\ Letícia Alves da Costa Laqua a, Camilla Daniela Moura-Nickel , Gláucia Maria Falcão Aragão ${ }^{a}$, Regina \\ de Fátima Peralta Muniz Moreira ${ }^{a}$. \\ ${ }^{a}$ Departamento de Engenharia Química e Engenharia de Alimentos, Universidade Federal de Santa Catarina, \\ CEP 88040-900, Florianópolis, SC, Brasil \\ ${ }^{b}$ Departamento de Engenharia Química, Universidade Tecnológica Federal do Paraná, CEP 85601-970, \\ Francisco Beltrão, PR, Brasil
}

Received: August 17, 2019; Revised: October 18, 2019; Accepted: November 10, 2019

In this study, porous microspheres of $\mathrm{TiO}_{2}\left(\mu \mathrm{TiO}_{2}\right)$ were synthesized, characterized and incorporated into an acrylic paint formulation to obtain a photocatalytically active paint. In a novel approach, the antifungal properties of the $\mu \mathrm{TiO}_{2}$ paint were evaluated using Monascus ruber as the representative microorganism and compared to those of a photocatalyst-free paint. The photocatalytic activity of paint films was determined by methylene blue (MB) degradation under real conditions of application. High photocatalytic and antifungal activity was observed, with the microorganism culture showing the formation of growth inhibition halos, typical of materials that produce biocides that diffuse into the culture medium.

Keywords: Active paint, fungicide, photoactivity, titanium dioxide, Monascus ruber.

\section{Introduction}

Photocatalytic paints are self-cleaning, since undesirable substances on the surface are removed through the simple incidence of light ${ }^{1}$. This photocatalytic activity, however, is not selective and in addition to pollutants the polymer paint matrix can be degraded ${ }^{1,2}$. Most research has been focused on photocatalytic paints formulated with anatase nanoparticles, due to their high photocatalytic activity ${ }^{3-8}$. However, nanoparticles, which have a high surface area, when homogeneously distributed in the film and under a light source, tend to rapidly degrade the paint film around them, causing photochalking ${ }^{1,9}$.

Therefore, the stability and the photocatalytic activity of paint films are two important aspects to consider in the development of an effective photocatalytic paint. It is necessary to achieve a balance between these two aspects, so that the paint is efficient without accelerating the autodegradation.

Different strategies have been proposed to improve the stability of acrylic photocatalytic paints ${ }^{10,11}$. One way to control the photocatalytic effect of titanium dioxide is to modify the particle morphology and size ${ }^{12-16}$. Among the various $\mathrm{TiO}_{2}$ morphologies reported, the mesoporous $\mathrm{TiO}_{2}$ spheres are notable for their high surface area and they allow a greater absorption of light due to a high crystallinity ${ }^{17,18}$. Recently, porous $\mathrm{TiO}_{2}$ microspheres with high specific surface area have been synthesized and applied in photovoltaic ${ }^{19,20}$ and photocatalytic ${ }^{21,22}$ technologies.

Hierarchical structures in the form of mesoporous $\mathrm{TiO}_{2}$ microspheres have been added to acrylic paint formulations to obtain paints with photocatalytic properties and greater stability in relation to photocatalytic paint containing commercial $\mathrm{TiO}_{2}$ nanoparticles ${ }^{1}$. The advantage of using a photocatalyst with high surface area, but with a diameter in the micrometric order, is the much lower contact of the active area with the paint surface, which reduces the degradation of the binder by photocatalysis ${ }^{1,23}$. Only tests to determine the photocatalytic activity and stability under severe aging conditions have been reported for the use of mesoporous $\mathrm{TiO}_{2}$ microspheres in paint formulations ${ }^{1}$. However, it is also important to ascertain the behavior of smart paints under the conditions of the environments in which they will be applied.

Most previous studies evaluated the $\mathrm{TiO}_{2}$ antimicrobial performance with bacteria such as Escherichia coli, commonly applied as the test microbe. The photocatalytic sensitivity of fungi was shown to be much weaker than bacteria due to their structural differences, particularly in the complexity and thickness of the cell envelope ${ }^{24}$. Nevertheless, there are still no concentrated studies focusing on the photocatalytic disinfection of fungi.

Fungi are generally considered the principal microflora on painted surfaces and they can enhance the paint degradation ${ }^{25,26}$. Moreover, they can live on the surface dirt or utilize the underlying substrate, causing allergies, respiratory symptoms, asthma, and serious health effects in people with suppressed immune systems ${ }^{27}$. Although several authors have evaluated the antifungal character of photocatalytic paints using Aspergillus niger as an environmental model, along with non-pathogen molds ${ }^{8,28,29}$, these fungal species were not found on deteriorated paint surfaces and, therefore, they are not considered as paint degraders ${ }^{25}$. A list of fungi and phototrophs detected on paint films was reported by Allsopp et al. ${ }^{30}$, and Monascus was one of the genera found. 
The main objective of this study was to evaluate the antifungal and photocatalytic properties of acrylic paints containing novel porous microspheres of $\mathrm{TiO}_{2}$. To the best of our knowledge, this is the first report of the antifungal properties of paint containing mesoporous microspheres of $\mathrm{TiO}_{2}$ evaluated using Monascus ruber as the representative microorganism. It is also the first time that results for the photocatalytic activity of paint containing $\mu \mathrm{TiO}_{2}$ have been obtained under real conditions of application in external (sunlight) and internal (UV light) environments. These important results demonstrate the applicability of photocatalytic paint containing $\mu \mathrm{TiO}_{2}$ and therefore represent a significant advance in the development of paints with photocatalytic and antifungal properties.

\section{Material and Methods}

The methylene blue dye (MB) was purchased from Lafan (Brazil). The formulated commercial acrylic-water base was supplied by a paint company (Anjo Tintas, Brazil) and contained water (42 wt.\%), extenders (15 wt.\%), binder slurry (38 wt.\%) and additive slurry (5 wt.\%).

\subsection{Synthesis of $\mathrm{TiO}_{2}$ microspheres}

The titanium dioxide microspheres $\left(\mu \mathrm{TiO}_{2}\right)$ were prepared using the methodology which combines a sol-gel method, a solvothermal treatment and a calcination process 1. In brief, $3.9 \mathrm{~g}$ of hexadecylamine (HDA, 90.0\%, SigmaAldrich) were mixed in $400 \mathrm{~mL}$ of ethanol absolute $(99.8 \%$, Neon) and $1.6 \mathrm{~mL}$ of $0.1 \mathrm{M} \mathrm{KCl} \mathrm{(A.R.,} \mathrm{Nuclear)} \mathrm{solution.}$ Then, $9.0 \mathrm{~mL}$ of titanium (IV) isopropoxide (TIP, $97.0 \%$, Sigma-Aldrich) was added dropwise under intense stirring, and the obtained suspension was allowed to stand for $24 \mathrm{~h}$. In sequence, the precipitate was filtered and washed with ethanol, thereby obtaining the amorphous $\mathrm{TiO}_{2}$ microspheres. The solvothermal treatment was carried out at $130{ }^{\circ} \mathrm{C}$ for $16 \mathrm{~h}$ in a Teflon-lined autoclave $(110 \mathrm{~mL})$ by adding $3.2 \mathrm{~g}$ of amorphous $\mathrm{TiO}_{2}$ microspheres to a mixture of $20 \mathrm{~mL}$ of distilled water and $40 \mathrm{~mL}$ of ethanol. The obtained precipitate was filtered, washed with ethanol absolute and dried at room temperature. Lastly, the $\mathrm{TiO}_{2}$ microspheres $\left(\mu \mathrm{TiO}_{2}\right)$ were calcined at $500{ }^{\circ} \mathrm{C}$ for $2 \mathrm{~h}$ under air atmosphere.

\subsection{Preparation of paint films}

The formulation of the photocatalytic paint was obtained by adding $10 \mathrm{wt} . \% \mu \mathrm{TiO}_{2}$ to an acrylic/water-based paint. The photocatalyst was added to the paint using a high-speed disperser with a high shear impeller (1700 rpm) for $1 \mathrm{~h}$.

Cement samples of approximately $4 \mathrm{~cm}^{2}$ were prepared. The surfaces were previously sanded and covered with two layers of paint. The drying time between each layer was 1 $\mathrm{h}$ and the final drying time was $24 \mathrm{~h}$.

\subsection{Characterization}

The morphology of $\mu \mathrm{TiO}_{2}$ was determined by scanning electron microscopy (SEM) and transmission electron microscopy (TEM) using a JEOL JSM-6390LV and JEOL JEM-1011 TEM microscope, respectively. For the SEM analysis, the powder samples were adhered to a metallic support with carbon tape and covered with gold. Prior to the TEM analysis, the samples were ultrasonically dispersed in ethanol as a solvent and then dried over a carbon grid.

The particle size distribution was obtained through dynamic light scattering (DLS) analysis using a particle size analyzer Nano-Flex S3000/S3500 Series Microtrac $®$. The samples were ultrasonically dispersed in distilled water $\left(10 \mathrm{~g} \mathrm{~L}^{-1}\right)$ for $1 \mathrm{~h}$. The refractive index used to detect the $\mathrm{TiO}_{2}$ particles in the analysis was $2.5^{31}$.

The morphology of the paint film surface was also determined by SEM analysis using the same equipment and, simultaneously, a semi-quantitative elemental chemical analysis was performed by energy-dispersive X-ray spectroscopy (EDX). As previously described, the paint films were also adhered to a metallic support with carbon tape and covered with gold.

Finally, the dry solids content of the paint films with and without $\mu \mathrm{TiO}_{2}$ was determined gravimetrically after the evaporation of all volatile material in an oven at $60{ }^{\circ} \mathrm{C}$ for $24 \mathrm{~h}$.

\subsection{Antifungal test}

The cement samples were placed in contact with the microorganisms Monascus ruber, since this fungal species is frequently found on degraded paint surfaces ${ }^{25}$. The inoculation was performed by the pour plate method in petri dishes using the appropriate growth medium (potato dextrose agar - PDA) ${ }^{32}$. After inoculation, the cement sample coated with photocatalytic paint and the cement sample containing a paint film without photocatalyst were placed in different petri dishes. Samples were incubated at $30{ }^{\circ} \mathrm{C}$ for $24 \mathrm{~h}$ and subsequently exposed to visible light for $48 \mathrm{~h}$. Control experiments under dark conditions were also performed and no antifungal effect was observed.

\subsection{Photocatalytic tests}

The cement samples coated with paint films received two layers of aqueous MB solution $\left(1 \mathrm{~g} \mathrm{~L}^{-1}\right)$. They were then dried and exposed to UVC light ( $8 \mathrm{~W}$ ) or sunlight (geographic coordinates: $27^{\circ} 35.8^{\prime} \mathrm{S} ; 48^{\circ} 32.95^{\prime} \mathrm{W}$ ), from 10:00 to $16: 00$ (December $12^{\text {th }}, 2017$ to January $31^{\text {st }}, 2018$ ). At regular intervals, samples were photographed to assess the change in the dye coloration. 


\section{Results and Discussion}

\subsection{Antifungal test}

The antifungal activity of titanium dioxide has been studied extensively ${ }^{33-36}$. However, most previous studies carried out with immobilized photocatalysts involve surfaces coated with $\mathrm{TiO}_{2}$ films ${ }^{37-40}$ and only a few authors report the antifungal activity of photocatalytic paint ${ }^{8,26,41,42}$. To the best of our knowledge, this is the first report of the antifungal properties of paint containing mesoporous microspheres of $\mathrm{TiO}_{2}$ evaluated using Monascus ruber as the representative microorganism.

According to Figure 1(a) and 1(c), an inhibition halo was clearly formed in the case of the samples coated with the photocatalytic paint and placed under visible light. This result could be attributed to the formation of oxidizing radicals, such as ${ }^{\circ} \mathrm{OH}$ or peroxides, capable of migrating to the culture medium and preventing the growth of the microorganisms, not only on the sample but also around it. In contrast, in the case of the paint without the photocatalyst, Figure 1(b), the inhibition of fungal growth was apparent only on top of the sample. Although the paint containing $\mathrm{TiO}_{2} \mathrm{P} 25$ has shown a more evident inhibition halo, the presence of these nanoparticles provokes a fast degradation of the paint film around them ${ }^{1,9}$.

The mechanisms for the primary events occurring at the catalyst surface have been well described ${ }^{43}$. The irradiation of $\mathrm{TiO}_{2}$ with photons of energy equal or greater than its band-gap $(\mathrm{Eg} \sim 3.2 \mathrm{eV})$ result in the promotion of electrons $\left(\mathrm{e}^{-}\right)$from the valence band to produce holes $\left(\mathrm{h}^{+}\right)$ at the conduction band of the particle (Eq 1):

$$
\mathrm{TiO}_{2}+\mathrm{hv} \rightarrow \mathrm{TiO}_{2}+\mathrm{e}^{-}+\mathrm{h}^{+}
$$

At the $\mathrm{TiO}_{2}$ particle surface, the holes $\left(\mathrm{h}^{+}\right)$react with surface hydroxyl groups $\left(\mathrm{OH}^{-}\right)$and adsorb $\mathrm{H}_{2} \mathrm{O}$, to form $\bullet \mathrm{OH}$ radicals (Eq 2 and 3 ).

$$
\mathrm{OH}^{-}+\mathrm{h}^{+} \rightarrow \cdot \mathrm{OH}
$$

$$
\mathrm{H}_{2} \mathrm{O}+\mathrm{h}^{+} \rightarrow \cdot \mathrm{OH}+\mathrm{H}^{+}
$$

In the absence of electron acceptors, the electron-hole recombination is possible. The presence of oxygen prevents this recombination by trapping electrons through the formation of superoxide ions (Eq. 4). The final product of the reduction may also be a radical (Eq. 5).

$$
\begin{gathered}
\mathrm{O}_{2}+e^{-} \rightarrow \mathrm{O}_{2}^{-} \\
2 \mathrm{O}_{2}^{--}+\mathrm{H}^{+} \rightarrow 2 \cdot \mathrm{OH}+\mathrm{O}_{2}
\end{gathered}
$$

The reactive oxygen species (ROS), such as hydroxyl radical, superoxide anions and hydrogen peroxide, generated on the surface, are considered responsible for the inactivation of the microorganism (Eq. 6)

$$
\text { Microorganisms }+ \text { ROS } \rightarrow \text { Inactivation }
$$

According to our studies, the mechanism of cell death or inhibition of microorganism growth was still not elucidated. The most accepted mechanism for microorganism inactivation by ROS indicates that the ${ }^{\bullet} \mathrm{OH}$ radicals or peroxides would initially promote the oxidation of the out membrane leading to a disorder in the cell permeability, even decomposition of the cell walls, and further oxidation of intracellular components that inhibit the cell respiration. The loss of the cell integrity could finally lead to the cell death. Another suggestion is that the ${ }^{\bullet} \mathrm{OH}$ radicals are not the only species responsible for the biocide effect, i.e., the co-operative action can also promote peroxidation of phospholipid components of the lipid membrane, responsible for essential functions as respiratory activity and cell death. ${ }^{24,44}$

It is important to note that the acrylic paint used in this study contains a small percentage of fungicide (around $0.2 \%$ ) in its formulation. However, fungicidal activity in the culture medium was not observed for the nonphotocatalytic paint sample and occurred only with the paint containing the $\mu \mathrm{TiO}_{2}$. This is due to the formation of oxidant species on the photocatalyst surface, activated by light.

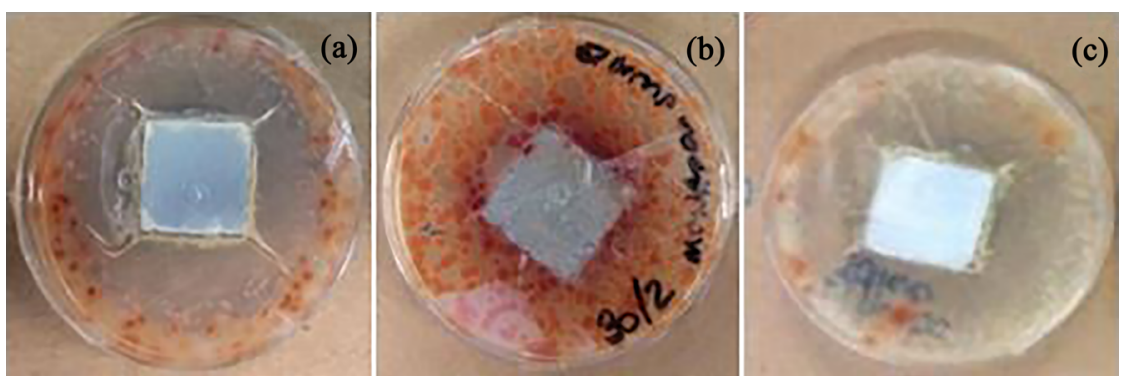

Figure 1. Paint films: (a) with $10 \% \mu \mathrm{TiO}_{2}$; (b) without $\mathrm{TiO}_{2}$ and (c) with $5 \% \mathrm{TiO}_{2} \mathrm{P} 25$, after the fungal test (Monascus ruber) under visible light. 
Thus, the photoactivity is related to the inhibition of the growth of the microorganisms by the action of radicals generated by the $\mathrm{TiO}_{2}$ microspheres under light irradiation.

\subsection{Photocatalytic tests}

The results for the methylene blue dye decolorization tests using the cement samples coated with photocatalytic paint $\left(\mu \mathrm{TiO}_{2}\right)$ under UVC light and sunlight are shown in Figure 2. It can be seen from Figure 2(a) that the MB decolorization under UVC light is fast, as expected.

After the initial color change, in which the characteristic blue color of the dye is removed, there are still components of the dye molecule adhered to the paint surface, giving a yellowish coloration, as also observed by Galenda et al. ${ }^{45}$ for commercial photocatalytic paints. According to Figure 2(b), the MB decolorization also occurs under sunlight. However, it is apparently slower than the process observed under UVC light, since the $\mu \mathrm{TiO}_{2}$ is more active under UVC light. Some authors have reported the degradation of dyes in photocatalytic paints containing nanoparticles and observed the removal of color over time ${ }^{9,46}$.

On the other hand, in addition to the degradation of the dye present on the paint surface, interaction between the mesoporous microspheres and the polymer matrix of the paint may occur. A scheme of the degradation of the acrylic paint film containing the mesoporous $\mathrm{TiO}_{2}$ microspheres produced in this study is shown in Figure 3. This mechanism consists of two stages of degradation after constant irradiation of the intact film by a light source: the initial photodegradation of the paint film and subsequently the exposure of the $\mu \mathrm{TiO}_{2}$. When the microspheres are exposed, pollutants and the irradiation can access the surface of the pores present within the particles, allowing the photocatalytic activity to be maintained or increased during the light exposure.

Particle size and surface area clearly play an important role in the dispersion and polymer-titanium dioxide interactions ${ }^{47}$. This is due to the fact that nanoparticles, such as $\mathrm{TiO}_{2} \mathrm{P} 25$ $(\sim 25 \mathrm{~nm})$, have a large outer surface area $\left(52.7 \mathrm{~m}^{2} \mathrm{~g}^{-1}\right)$, being generally characterized as non-porous ${ }^{1,48}$. Thus, the $\mu \mathrm{TiO}_{2}$ in this study, due to the micrometric dimensions and mesoporosity, has a smaller outer surface area, most of the surface area of this photocatalyst being located inside the mesopores. Therefore, the area effectively in contact with the polymer matrix of the paint is reduced, increasing the stability of the photocatalytic paint obtained with this photocatalyst $\left(\mu \mathrm{TiO}_{2}\right)$, as verified by Amorim et al. ${ }^{1}$.

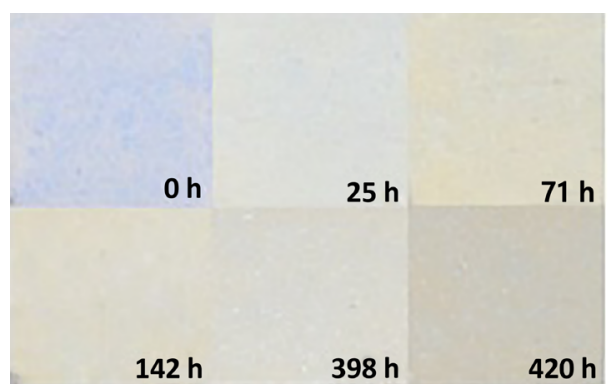

(a)

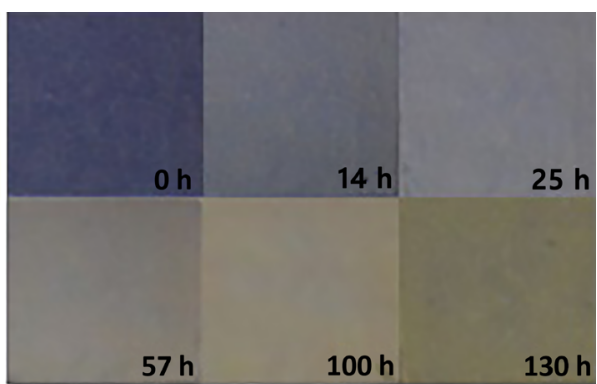

(b)

Figure 2. Decolorization of $\mathrm{MB}$ using photocatalytic paint $\left(10 \% \mu \mathrm{TiO}_{2}\right)$ under (a) $\mathrm{UVC}$ and (b) sunlight.

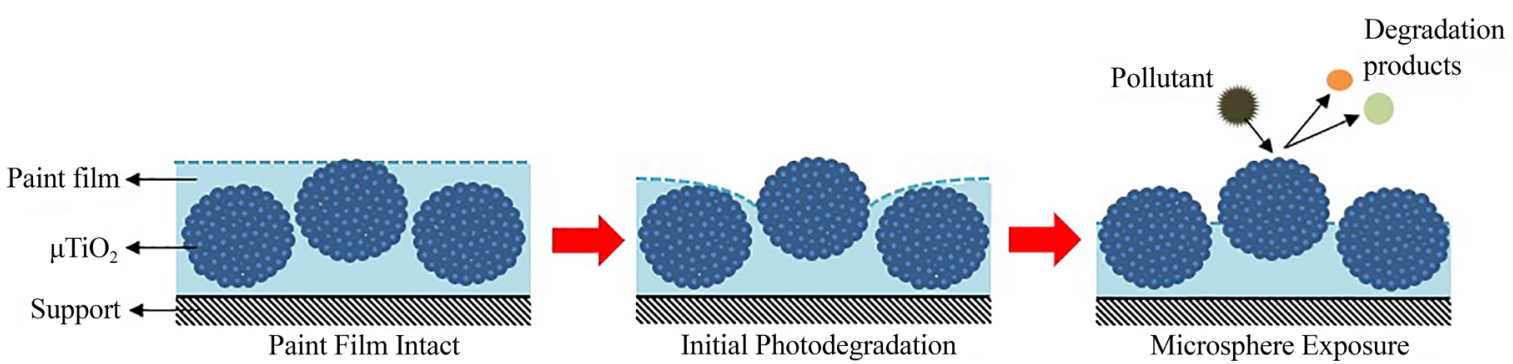

Figure 3. Scheme proposed for interactions in a paint film containing mesoporous $\mathrm{TiO}_{2}$ microspheres. 


\subsection{Characterization}

SEM and TEM analyses (Figure 4(a) and (b)) were performed to obtain high resolution images of the particle morphology of the $\mu \mathrm{TiO}_{2}$. The particles show a spherical shape and micrometric size. Also, the particles surface is rough and irregular (Figure 4(b)). This porous structure is formed due to the elimination of hexadecylamine (driving agent with boiling point of $330^{\circ} \mathrm{C}$ ) in the calcination step at $500{ }^{\circ} \mathrm{C}$, causing the rupture of the microspheres ${ }^{1,19}$.

According to the porous structure analysis, the average pore size of the $\mu \mathrm{TiO}_{2}$ was $13 \mathrm{~nm}{ }^{1}$, which is typical for mesoporous materials (2-50 nm) according to IUPAC ${ }^{24}$. The $\mathrm{N}_{2}$ adsorption-desorption isotherm at $77 \mathrm{~K}$ is classified as a type IV isotherm with a hysteresis $\mathrm{H} 2$ loop $^{1}$, and according to IUPAC classification this is characteristic of mesoporous materials ${ }^{49}$.

The particle size distribution curve for the $\mu \mathrm{TiO}_{2}$ is shown in Figure 5. Titanium microspheres have a uniform particle size distribution in the range of 600 to $1300 \mathrm{~nm}$ with a maximum peak at $945 \mathrm{~nm}$ (which is the effective diameter). This result confirms the micrometric dimensions observed in the SEM and TEM images (Figs. 5(a) and (b)).

In order to evaluate the morphology and to identify differences related to the addition of $\mu \mathrm{TiO}_{2}$ in the paint formulation, the surfaces of the paint films were analyzed by scanning electron microscopy and the images are presented in Figure 6. At the base of the paint film, Figure 6(a), large insoluble particles can be seen and these are attributed to other components, such as extenders or additives ${ }^{1,50}$. The paint film with $\mu \mathrm{TiO}_{2}$, Figure 6(b), shows the presence of the microspheres on the paint surface (some highlighted by circles), which is not observed in Figure 6(a). The $\mu \mathrm{TiO}_{2}$ particles are partly exposed on the surface and some are agglomerated. The importance of good dispersion is characterized by the need to minimize contact between the microspheres and the polymer matrix of the paint and consequently reduce the degradation, according to the mechanism proposed in Figure 3.
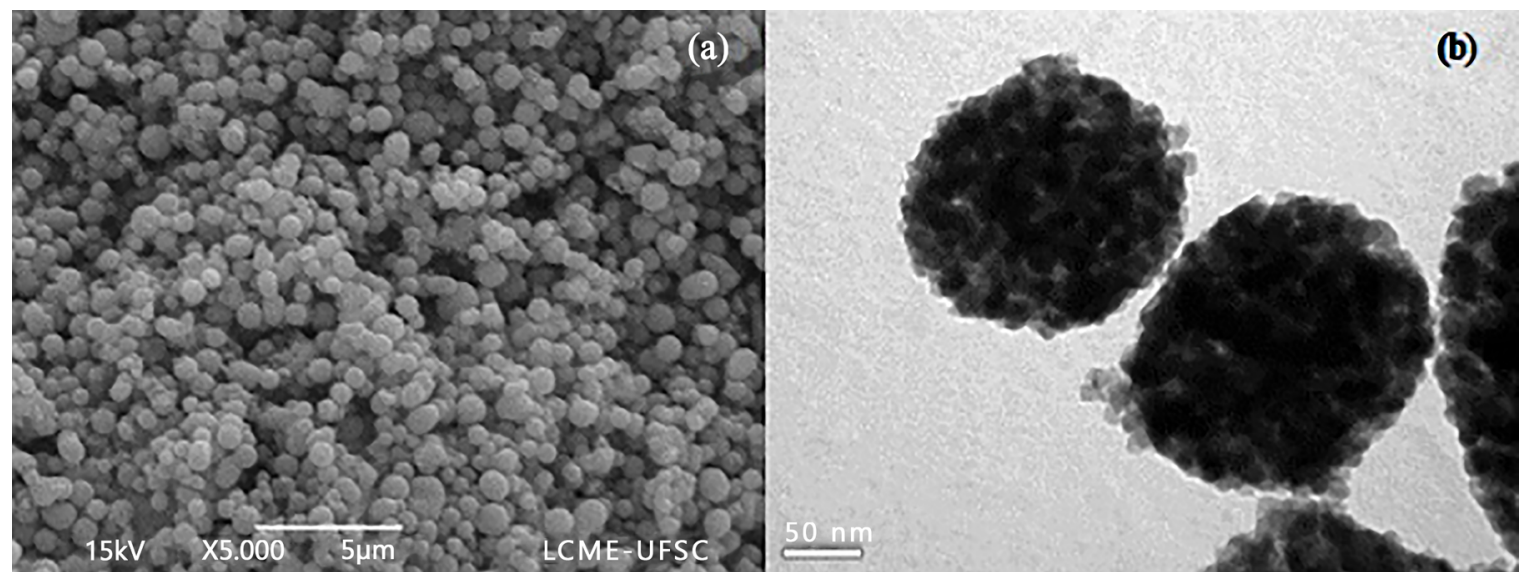

Figure 4. (a) SEM and (b) TEM images of the $\mu \mathrm{TiO}_{2}$

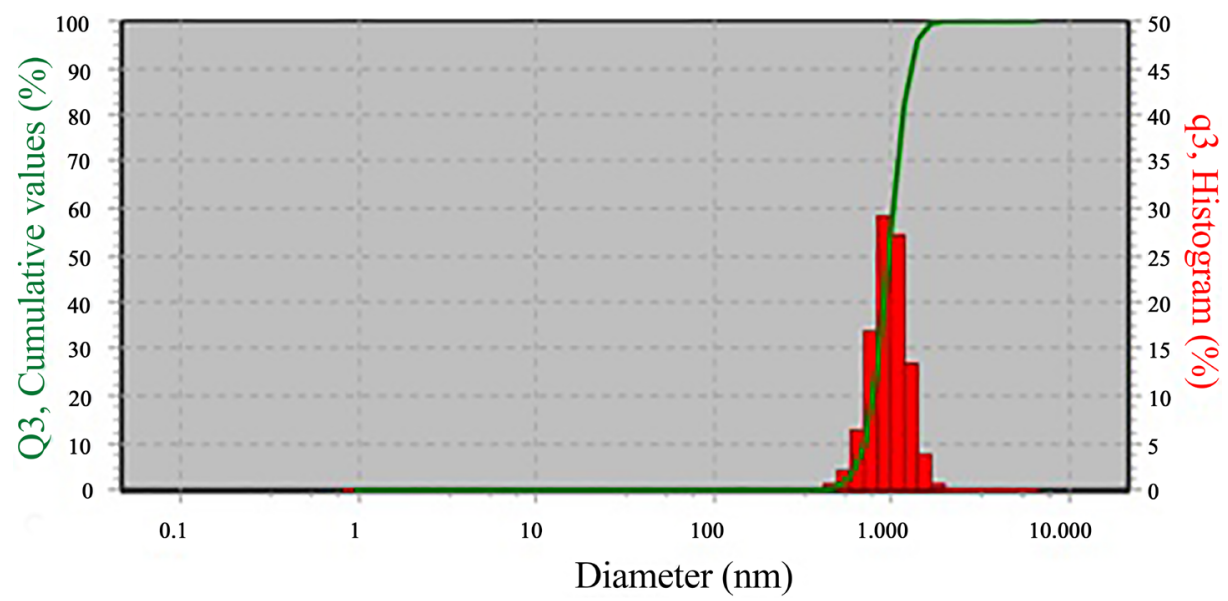

Figure 5. Particle size distribution of $\mu \mathrm{TiO}_{2}$. 

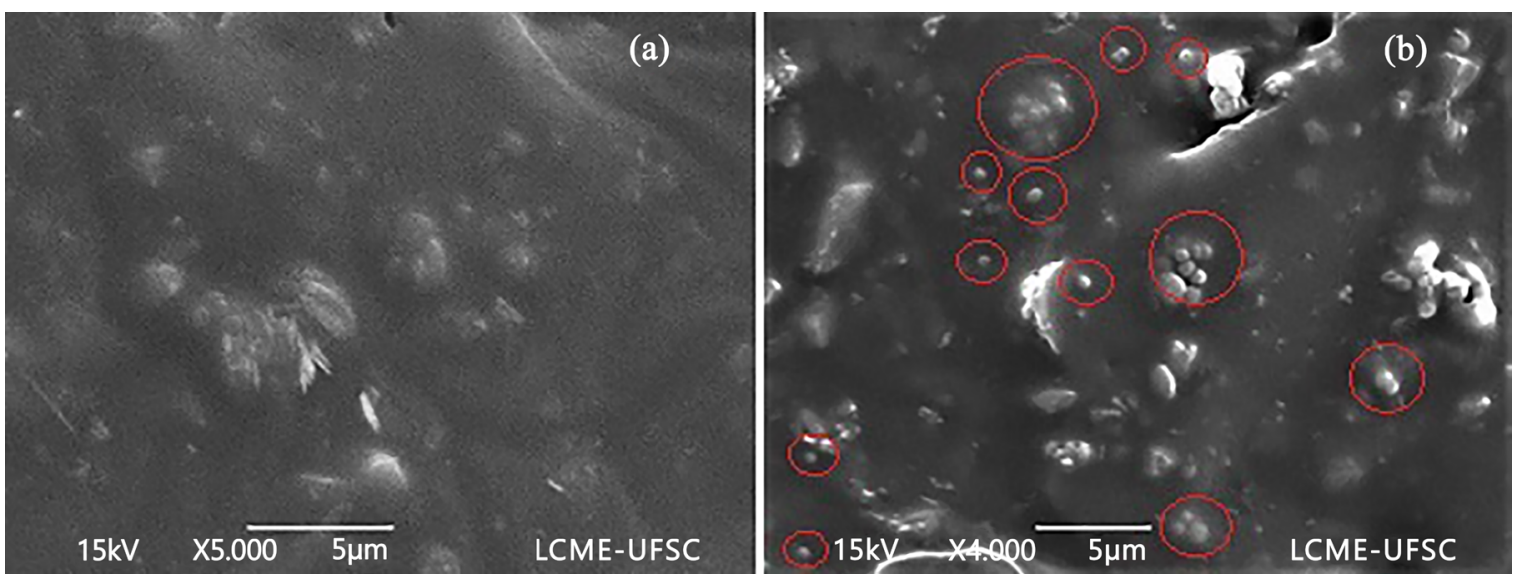

Figure 6. SEM images of the paint (a) without and (b) with $\mu \mathrm{TiO}_{2}$.

Table 1. Semi-quantitative results for the chemical elements and values for the total dry solids content in paint samples with and without $\mu \mathrm{TiO}$.

\begin{tabular}{cccccccccc}
\hline & $\begin{array}{c}\text { Dry solids } \\
\text { (wt.\%) }\end{array}$ & \multicolumn{7}{c}{ Elements (wt. \%) } \\
\cline { 3 - 9 } & & $\mathrm{C}$ & $\mathrm{O}$ & $\mathrm{Mg}$ & $\mathrm{Al}$ & $\mathrm{Si}$ & $\mathrm{Ca}$ & $\mathrm{Ti}$ \\
\hline Paint base & 36.34 & 73.29 & 18.02 & 0.28 & 2.17 & 2.06 & 4.18 & - \\
Paint $\left(+\mu \mathrm{TiO}_{2}\right)$ & 44.21 & 66.40 & 20.34 & 0.27 & 1.66 & 2.47 & 4.40 & 4.46 \\
\hline
\end{tabular}

The solids content of each paint was determined and the results are reported in Table 1. The final dry film is composed of the resin, extenders and additives present in the paint formulations. The percentage of dry solids in the paint $\left(+\mu \mathrm{TiO}_{2}\right)$ increased by around $8 \mathrm{wt} . \%$, which corresponds to the $10 \mathrm{wt} . \%$ of titanium dioxide microspheres initially added.

To confirm the presence of the titanium dioxide microspheres in the photocatalytic paint, semi-quantitative EDX analysis was performed and the results for the elemental composition are shown in Table 1. The paint containing $\mu \mathrm{TiO}_{2}$ presented titanium as an additional element in its composition, in contrast to the paint base, which confirms the presence of the titanium dioxide in the formulation. However, the percentage was below the nominal value of $10 \mathrm{wt} . \%$, indicating a nonuniform distribution of the $\mathrm{TiO}_{2}$ microspheres in the film, as observed in the SEM image, Figure 6(b).

The durability of acrylic paint containing $\mu \mathrm{TiO}_{2}$, with photocatalytic properties, has been demonstrated in a previous study ${ }^{1}$. Paint prepared with $\mu \mathrm{TiO}_{2}$ was found to be more stable than paint containing $\mathrm{TiO}_{2} \mathrm{P} 25$ nanoparticles and exhibited degradation similar to that of a commercial paint containing $\mathrm{TiO}_{2}$ rutile (non-catalytic pigment) under the same extreme conditions applied in the cyclic analysis ${ }^{1}$. The use of $\mathrm{TiO}_{2}$ with micrometric dimensions and a porous structure (Figure 5) can greatly reduce the contact area between the photocatalyst and the organic binder, leading to its enhanced durability. In addition, important results presented herein show, for the first time, the possibility of applying this smart paint containing mesoporous $\mathrm{TiO}_{2}$ microspheres under real aging conditions to combat the accumulation of microorganisms and pollutants on surfaces.

\section{Conclusions}

This paper reports a study on the antifungal and photocatalytic activity of an acrylic paint containing synthesized $\mathrm{TiO}_{2}$ microspheres. The fungicidal activity of the paint was verified through the production and release of oxidizing species in the culture medium. These species are responsible for preventing the growth of microorganisms (Monascus ruber) and consequently a characteristic inhibition halo is formed around the sample containing $\mu \mathrm{TiO}_{2}$. In addition to the fungicidal activity, the photocatalytic activity of the paint with $\mu \mathrm{TiO}_{2}$, under UVC and solar light, was evidenced from $\mathrm{MB}$ dye degradation over time.

\section{Acknowledgments}

This research was financially supported by the Brazilian governmental agencies CAPES and CNPq. The authors would like to thank LCME-UFSC for technical support provided during the electron microscopy work, and Anjo Tintas for supplying the samples of acrylic paint used to conduct the tests.

\section{References}

1. Amorim SM, Suave J, Andrade L, Mendes A, José HJ, Moreira RFPM. Towards an efficient and durable self-cleaning acrylic paint containing mesoporous $\mathrm{TiO}_{2}$ microspheres. Progress in Organic Coatings. 2018;118:48-56.

2. Allen NS, Edge M, Sandoval G, Verran J, Stratton J, Maltby J. Photocatalytic coatings for environmental applications. Photochemistry and Photobiology. 2005;81(2):279-90. 
3. Auvinen J, Wirtanen L. The influence of photocatalytic interior paints on indoor air quality. Atmospheric Environment. 2008;42(18):4101-12.

4. Águia C, Ângelo J, Madeira LM, Mendes A. Influence of photocatalytic paint components on the photoactivity of P25 towards NO abatement. Catalysis Today. 2010;151(1):77-83.

5. Geiss O, Cacho C, Barrero-Moreno J, Kotzias D. Photocatalytic degradation of organic paint constituents-formation of carbonyls. Building and Environment. 2012;48:107-12.

6. Tryba B, Wrobel RJ, Homa P, Morawski AW. Improvement of photocatalytic activity of silicate paints by removal of $\mathrm{K}_{2} \mathrm{SO}_{4}$. Atmospheric Environment. 2015;115:47-52.

7. Ângelo J, Andrade L, Mendes A. Highly active photocatalytic paint for NOx abatement under real-outdoor conditions. Applied Catalysis A: General. 2014;484:17-25.

8. Zacarías SM, Marchetti S, Alfano OM, Ballari MM. Photocatalytic paint for fungi growth control under different environmental conditions and irradiation sources. Journal of Photochemistry and Photobiology A: Chemistry. 2018;364:76-87.

9. Baudys M, Krýsa J, Mills A. Smart inks as photocatalytic activity indicators of self-cleaning paints. Catalysis Today. 2017;280(Pt 1):8-13

10. Scalarone D, Lazzari M, Chiantore O. Acrylic protective coatings modified with titanium dioxide nanoparticles: Comparative study of stability under irradiation. Polymer Degradation and Stability. 2012;97(11):2136-42.

11. Nguyen TV, Nguyen PNT, Nguyen TD, El Aidani R, Trinh VT, Decker C. Accelerated degradation of water borne acrylic nanocomposites used in outdoor protective coatings. Polymer Degradation and Stability. 2016;128:65-76.

12. Song H, Cheng K, Guo H, Wang F, Wang J, Zhu N, et al. Effect of ethylene glycol concentration on the morphology and catalytic properties of $\mathrm{TiO}_{2}$ nanotubes. Catalysis Communications. 2017;97:23-26.

13. Ling Y, Zhang C, Wu J, Xu W, Qi Y, He P, et al. Enhanced photocatalytic activity of $\mathrm{TiO}_{2}$ by micrometer-scale flower-like morphology for gaseous elemental mercury removal. Catalysis Communications. 2018;116:91-5.

14. Gonçalves P, Bertholdo R, Dias JA, Maestrelli SC, Giraldi TR. Evaluation of the photocatalytic potential of $\mathrm{TiO}_{2}$ and $\mathrm{ZnO}$ obtained by different wet chemical methods. Materials Research. 2017;20(Suppl 2):181-9.

15. Ribeiro PC, Costa ACFM, Kiminami RHGA, Sasaki JM, Lira HL. Synthesis of $\mathrm{TiO}_{2}$ by the pechini method and photocatalytic degradation of methyl red. Materials Research. 2012;16(2):468-72.

16. Filippo E, Carlucci C, Capodilupo AL, Perulli P, Conciauro F, Corrente GA, et al. Enhanced photocatalytic activity of pure anatase $\mathrm{TiO}_{2}$ and $\mathrm{Pt}-\mathrm{TiO}_{2}$ nanoparticles synthesized by green microwave assisted route. Materials Research . 2015;18(3):473-81.

17. Wang F, Qian X, Li X, Ye J, Han Z, Chen Y, et al. Optical-thermal properties of reduced $\mathrm{TiO}_{2}$ microspheres prepared by flame spraying. Materials Letters. 2015; 151:82-4.
18. Yang Y, Wang G, Liang Y, Yuan C, Yu T, Li Q, et al. Enhanced photocatalytic performance of Ag decorated hierarchical micro/nanostructured $\mathrm{TiO}_{2}$ microspheres. Journal of Alloys and Compounds. 2015;652:386-92.

19. Chen D, Cao L, Huang F, Imperia P, Cheng YB, Caruso RA. Synthesis of monodisperse mesoporous titania beads with controllable diameter, high surface areas, and variable pore diameters (14-23 nm). Journal of the American Chemical Society. 2010;132(12):4438-44.

20. Chen D, Huang F, Cao L, Cheng YB, Caruso RA. Spiky mesoporous anatase titania beads: a metastable ammonium titanate-mediated synthesis. Chemistry. 2012;18(43):13762-9.

21. Liu W, Xu Y, Zhou W, Zhang X, Cheng X, Zhao H, et al. A facile synthesis of hierarchically porous $\mathrm{TiO}_{2}$ microspheres with carbonaceous species for visible-light photocatalysis. Journal of Materials Science and Technology. 2017;33(1):39-46.

22. Wang X, Cao L, Chen D, Caruso RA. Engineering of monodisperse mesoporous titania beads for photocatalytic applications. ACS Applied Materials and Interfaces. 2013;5(19):9421-8.

23. Gunnarsson SG. Self cleaning paint: Introduction of photocatalytic particles into a paint system. Kongens Lyngby: Technical University of Denmark; 2012.

24. Seven O, Dindar B, Aydemir S, Metin D, Ozinel M, Icli S. Solar photocatalytic disinfection of a group of bacteria and fungi aqueous suspensions with $\mathrm{TiO}_{2}, \mathrm{ZnO}$ and Sahara desert dust. Journal of Photochemistry and Photobiology A: Chemistry. 2004;165(1-3):103-7.

25. Gaylarde CC, Morton LHG, Loh K, Shirakawa MA. Biodeterioration of external architectural paint films - A review. International Biodeterioration and Biodegradation. 2011;65(8):1189-98.

26. Pittol M, Tomacheski D, Simões DN, Ribeiro VF, Santana RMC. Antimicrobial performance of thermoplastic elastomers containing zinc pyrithione and silver nanoparticles. Materials Research. 2017;20(5):1266-73.

27. Chen F, Yang X, Wu Q. Antifungal capability of $\mathrm{TiO}_{2}$ coated film on moist wood. Building and Environment. 2009;44(5):1088-93.

28. Markowska-szczupak A, Ulfig K, Grzmil BU, Morawski AW. A preliminary study on antifungal effect of $\mathrm{TiO}_{2}$-based paints in natural indoor light. Polish Journal of Chemical Technology. 2010;12(4):53-7.

29. Zuccheri T, Colonna M, Stefanini I, Santini C, Gioia DD. Bactericidal activity of aqueous acrylic paint dispersion for wooden substrates based on $\mathrm{TiO}_{2}$ nanoparticles activated by fluorescent light. Materials (Basel). 2013;6(8):3270-83.

30. Allsopp D, Seal K, Gaylarde C. Biodeterioration of refined and processed materials. In: Allsopp D, Seal K, Gaylarde C, editors. Introduction to biodeterioration. $2^{\text {nd }}$ ed. Cambridge: Cambridge University Press; 2004. p. 78-85.

31. Wojciechowski K, Zukowska GZ, Korczagin I, Malanowski P. Effect of $\mathrm{TiO}_{2}$ on UV stability of polymeric binder films used in waterborne facade paints. Progress in Organic Coatings. 2015;85:123-30. 
32. National Committee for Clinical Laboratory Standards (NCCLS). Performance standards for antimicrobial disk susceptibility tests for bacteria that grow aerobically - Approved Standard NCCLS document M2-A8. $8^{\text {th }}$ ed. Wayne: NCCLS; 2003.

33. Beltrán-Partida E, Valdez-Salas B, Curiel-Álvarez M, CastilloUribe S, Escamilla A, Nedev N. Enhanced antifungal activity by disinfected titanium dioxide nanotubes via reduced nano-adhesion bonds. Materials Science and Engineering: C. 2017;76:59-65.

34. Filpo G, Palermo AM, Rachiele F, Nicoletta FP. Preventing fungal growth in wood by titanium dioxide nanoparticles. International Biodeterioration and Biodegradation. 2013;85:217-22.

35. Sundrarajan M, Bama K, Bhavani M, Jegatheeswaran S, Ambika S, Sangili A, et al. Obtaining titanium dioxide nanoparticles with spherical shape and antimicrobial properties using $M$. citrifolia leaves extract by hydrothermal method. Journal of Photochemistry and Photobiology B: Biology. 2017; 171:117-24.

36. Pokhum C, Viboonratanasri D, Chawengkijwanich C. New insight into the disinfection mechanism of Fusarium monoliforme and Aspergillus niger by $\mathrm{TiO}_{2}$ photocatalyst under low intensity UVA light. Journal of Photochemistry and Photobiology B: Biology. 2017;176:17-24.

37. Vučetić SB, Rudić OLJ, Markov SL, Bera OJ, Vidaković AM, Skapin ASS, et al. Antifungal efficiency assessment of the $\mathrm{TiO}_{2}$ coating on façade paints. Environmental Science and Pollution Research. 2014;21(19):11228-37.

38. Kitamura T, Ali AMD, Matjalina NFB, Hussin HMRBH, inventors. Anti-bacterial and anti-fungal photocatalytic coating film and method for producing thereof. US patent 20180035667. 2017 Aug 08.

39. Huang L, Jing S, Zhuo O, Meng X, Wang X. Surface hydrophilicity and antifungal properties of $\mathrm{TiO}_{2}$ films coated on a $\mathrm{Co}-\mathrm{Cr}$ substrate. Biomed Research International. 2017;2054723.

40. Goffredo GB, Citterio B, Biavasco F, Stazi F, Barcelli S, Munafò P. Nanotechnology on wood: The effect of photocatalytic nanocoatings against Aspergillus niger. Journal of Cultural Heritage. 2017;27:125-36.
41. Zhao Y, Huang Z, Chang W, Wei C, Feng X, Ma L, et al. Microwave-assisted solvothermal synthesis of hierarchical $\mathrm{TiO}_{2}$ microspheres for efficient electro-field-assisted-photocatalytic removal of tributyltin in tannery wastewater. Chemosphere. 2017;179:75-83.

42. Hochmannová L, Vytrasová J. Photocatalytic and antimicrobial effects of interior paints. Progress in Organic Coatings. 2010;67(1):1-5.

43. Matsunaga T, Tomoda R, Nakajima T, Wake H. Photoelectrochemical sterilization of microbial cells by semiconductor powders. FEMS Microbiology Letters. 1985;29(1-2):211-4.

44. Maness PC, Smolinski S, Blake DM, Huang Z, Wolfrum EJ, Jacoby WA. Bactericidal activity of photocatalytic $\mathrm{TiO}_{2}$ reaction: toward an understanding of its killing mechanism. Applied and Environmental Microbiology. 1999;65(9):4094-4098.

45. Galenda A, Visentin F, Gerbasi R, Favaro M, Bernardi A, El Habra N. Evaluation of self-cleaning photocatalytic paints: Are they effective under actual indoor lighting systems?. Applied Catalysis B: Environmental. 2018;232:194-204.

46. Pal S, Contaldi V, Licciulli A, Marzo F. Self-cleaning mineral paint for application in architectural heritage. Coatings. 2016;6(4):48.

47. Allen NS, Edge M, Ortega A, Sandoval G, Liauw CM, Verran J, et al. Degradation and stabilisation of polymers and coatings: Nano versus pigmentary titania particles. Polymer Degradation and Stability. 2004;85(3):927-46.

48. Baldissarelli VZ, Souza T, Andrade L, Oliveira LFC, José HJ, Moreira RFPM. Preparation and photocatalytic activity of $\mathrm{TiO}_{2}-$ exfoliated graphite oxide composite using an ecofriendly graphite oxidation method. Applied Surface Science. 2015; 359:868-74.

49. Burwell RL. Manual of symbols and terminology for physicochemical quantities and units-Appendix II Heterogeneous Catalysis. Advances in Catalysis. 1977;26:351-92.

50. Tryba B, Homa P, Wróbel RJ, Morawski AW. Photocatalytic decomposition of benzo-[a]-pyrene on the surface of acrylic, latex and mineral paints. Influence of paint composition. Journal of Photochemistry and Photobiology A: Chemistry. 2014;286:10-5. 